\title{
The quality of water used for irrigation of agricultural soil in the basin of Kolubara river
}

\author{
Radmila Pivic *, Zoran Dinic, Dragana Josic, Aleksandra Stanojkovic Sebic \\ Institute of Soil Science, Belgrade, Serbia \\ *Corresponding author e-mail : drradmila@pivic.com \\ Received: 15.12.2013 \\ Accepted: 14.04.1014
}

\begin{abstract}
This paper presents the results of testing the quality of water for irrigation during the growing seasons 2012/2013, in the basin of the Kolubara River, from Beloševac to Obrenovac, in three monitoring cycles on 16 selected sites belonging to agricultural area under irrigation. The determination of quantity of trace elements and heavy metals $\mathrm{Cr}$, Ni, Pb, Cu, Zn, Cd, B, As, Fe, Hg was performed during mentioned period. The content of trace elements and heavy metals in the samples of water is generally below the maximum allowable concentration (MAC). In the samples No. 2, 3, 4, in the second series of sampling was recorded higher content of As above the MAC, which can be explained by drought, low water levels and potential anthropogenic pollution. In the other two cycles of monitoring are not registered concentrations of tested elements above MAC. Based on the presented and analyzed results of testing of hazardous and harmful substances in the water for irrigation of the Kolubara River, it can be concluded that it can be used for irrigation of crops and soil with restrictions and frequent quality checks during the summer months and control potential sources of pollution from industry.
\end{abstract}

Keywords: Harmful substances, irrigation water, soil

\section{INTRODUCTION}

The scope of the research conducted in this paper is the study of quality of irrigation water from the Kolubara River, complies with the requirements of FAO, 1954 and U.S. Salinity Laboratory classification, designed for usability evaluation of irrigation water (Doneen and Westcot, 1988). Irrigation means the artificial watering the soil in order to wet the rhizosphere layer at a time when the amount of available soil moisture is insufficient to meet the optimum energy for crops. Irrigation is a hydro-reclamation measure that aims to improve the physical properties of the soil by adding water to achieve optimum moisture during the growing season and thus achieve optimum yield. It may be applied during part of the growing season or during the whole growing season. Irrigation of cultivated plants on agricultural soil involves the use of water of appropriate physical, chemical and biological properties, so it is very important to examine the quality of water used for its intended purpose in order to assess the impact on soil and plants. Intensification of irrigation depends primarily on the provision to the required amount of water of adequate quality.
The major proportion of all water quality degradation worldwide is due to anthropogenic causes (Faniran et al., 2001; Simeonov et al., 2003). The accumulation of metals in an aquatic environment has direct consequences to man and to the ecosystem (Fatoki et al., 2005).

In less industrialized areas like the Kolubara basin, pollution from human settlements lacking appropriate sanitary infrastructure, partially treated or untreated wastewater, leachates from refuse dumps and from land-use activities such as agriculture, are the major pollution sources to the surface water (http://en.wikipedia.org/wiki/Kolubara). In terms of provision of water resources, Republic of Serbia is well-provided. It is estimated that the amount of surface water per capita during the year is about $2973 \mathrm{~m}^{3}$, while the amount of groundwater is around $4500 \mathrm{~m}^{3}$ per year. The water resources are great, but not conveniently distributed in relation to the needs of agricultural production. In Serbia, in most locations occurs a deficit of soil moisture during the growing season, so that almost everywhere it is necessary to perform a permanent or temporary 
irrigation. It is evident that for the study area the irrigation can be used as an additional measure in the period from July to the end of October.

The aim of this study is to assess the current water quality of the Kolubara River in order to be used for irrigation of agricultural soil near the streams and highlight the pollution risk.

\section{MATERIAL AND METHODS}

\section{Description of the study area}

Kolubara is a river in western Serbia with the length of $123 \mathrm{~km}$, and belongs to the rivers with medium-length. Kolubara River rises near Valjevo, from rivers Obnica and Jablanica, and flows into the Sava River near Obrenovac. In the Kolubara basin, of a $3639 \mathrm{~km}^{2}$ area, there are rich deposits of lignite. Through the valley of Kolubara the railway and highway passes. Kolubara River, as well as all its tributaries, belongs to the rivers with the rain - snow water regime. An important characteristic of the water regime presents the sudden and large fluctuations in water levels and flows. In geological terms, along the Kolubara River alluvial deposits of very heterogeneous

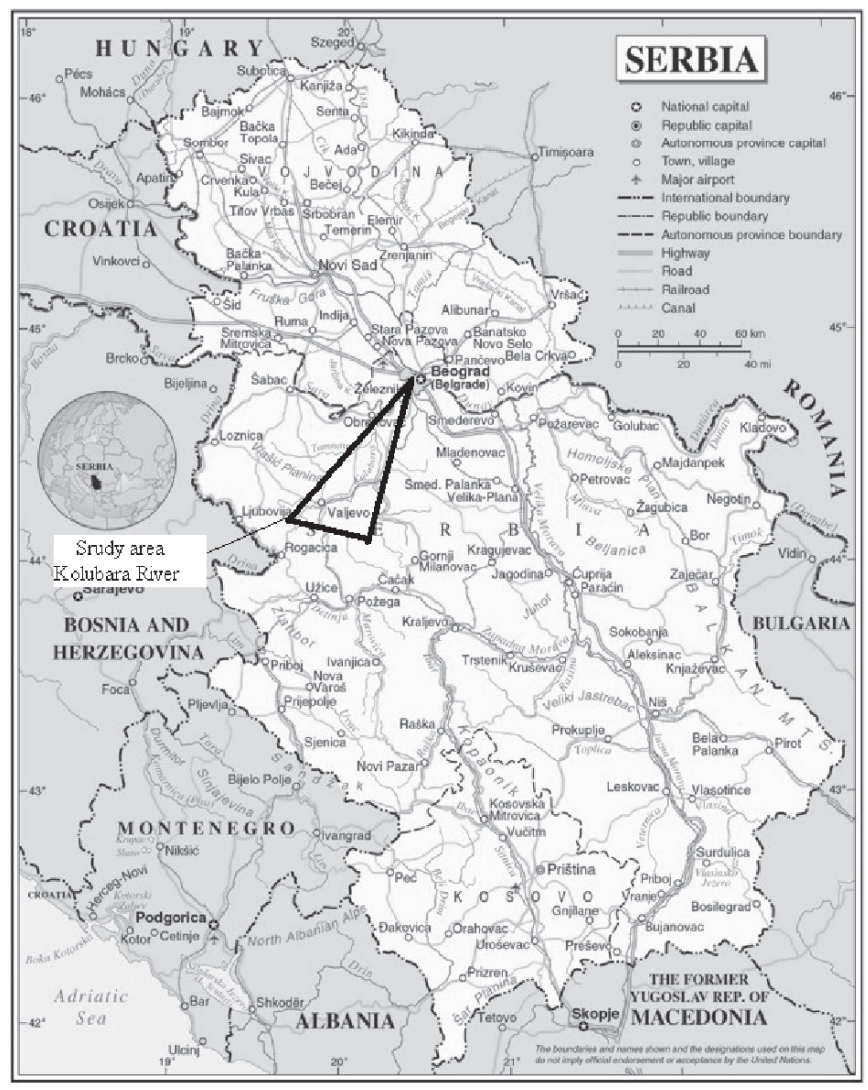

composition are present, therefore, the soils formed on them are also very heterogeneous. A drift along the Kolubara is of finer structure and it preserved its characteristic features. Under influence of high groundwater and hydrophilic vegetation it underwent changes and has evolved to hydro genic soil types.

Kolubara river basin has a form of an irregular quadrilateral, and the distance between the most western point (19 $39^{\circ}$ of east longitude) and the most eastern point (20 $35^{\prime}$ of east longitude), which are in the west-east direction, is $81.2 \mathrm{~km}$. The distance between the most northern point (44 $40^{\circ}$ of north latitude) and the most southern point ( $44^{\circ} 05^{\prime}$ of north latitude), which are in the north-south direction, is $64 \mathrm{~km}$. The highest point in the basin is $1346 \mathrm{~m}$, and the lowest - at an altitude of $73 \mathrm{~m}$. Average altitude of the relief in the Kolubara valley is $276.4 \mathrm{~m}$.

Pseudogley soils, which cover the largest area in the Kolubara valley of approximately $25 \%$, are located on flat and gently rolling terrain of usually ancient alluvial river terraces. The most common are at altitudes of $150-350 \mathrm{~m}$. These are very

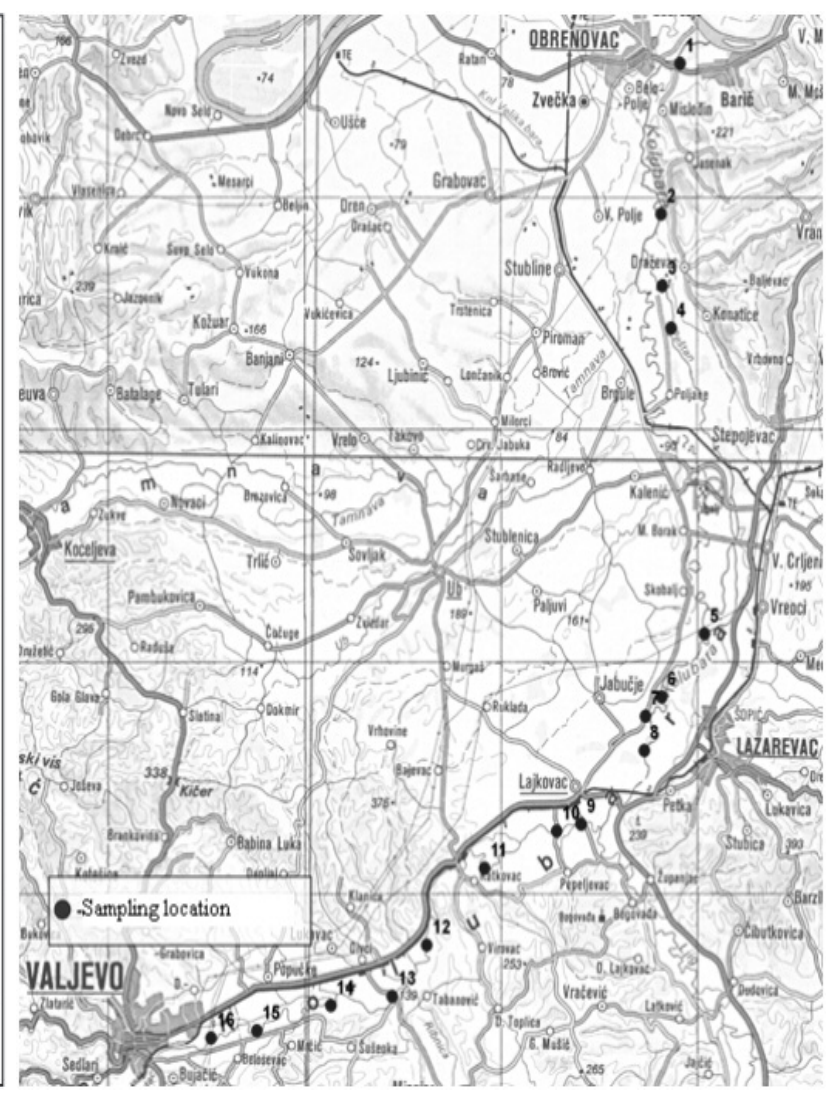

Figure 1. Location map of Kolubara valley with selected sample sites 
acidic soils, poor in clay, humus and nutrients. Those soils have unfavorable chemical and waterair properties and low water permeability. In the Kolubara valley it is very frequent a group of brown soils (Distric Cambisols), which are formed on different geological substrates. Large parts of the river valleys in the Kolubara basin are covered with meadow soils (Semigley). Regarding the nutrient content, they belong to the group of very rich soil (Tanasijević et al., 1966). The average annual precipitation in the study area is about $730 \mathrm{~mm}$ and the mean annual temperature is relatively high and vary between $11.4-12.5^{\circ} \mathrm{C}$. Distribution of rainfall during the year is quite unfavorable.

\section{Sampling and collection of water samples}

A total of 48 water samples were collected from 16 (sixteen) sampling points (Table 1). Water samples were collected in three cycles of sampling, in July and October 2012 and April 2013, using $2000 \mathrm{ml}$ plastic bottles. The sampling bottles for heavy metal determination were presoaked overnight with $10 \% \mathrm{HCl}$, then, rinsed with distilled water and also rinsed using river water before sample collection. Sampling bottles for the determination of physicochemical parameters were cleaned and rinsed using distilled water only. Preservation of water samples was done by adding 2 drops of concentrated $\mathrm{HNO}_{3}$ to each water sample before storage below $4^{\circ} \mathrm{C}$ until it was analyzed.

Table 1. Sampling points along the Kolubara river.

\begin{tabular}{ccc}
\hline Sampling point & Easting & Northing \\
\hline 1 & 7439160 & 4945800 \\
2 & 7438190 & 4939310 \\
3 & 7438260 & 4936220 \\
4 & 7438710 & 4934390 \\
5 & 7440400 & 4921220 \\
6 & 7438240 & 4918480 \\
7 & 7437410 & 4917660 \\
8 & 7437340 & 4916170 \\
9 & 7434120 & 4913000 \\
10 & 7432880 & 4912710 \\
11 & 7429220 & 4911110 \\
12 & 7426250 & 4907780 \\
13 & 7424500 & 4905570 \\
14 & 7421370 & 4905180 \\
15 & 7417600 & 4904100 \\
16 & 7415280 & 4903790
\end{tabular}

\section{Analytical methods}

The measured parameters were determined by the following methods: $\mathrm{pH}$-potentiometric (SRPS H.Z1.111:1987), electrical conductivity (ECW)conductiometric (SRPS EN 27888:1993), total dissolved solids (TDS)-gravimetric (Greenberg et al., 1998). The acid-available fraction of heavy metals and other toxic elements (As, B, Cd, Cr, $\mathrm{Cu}, \mathrm{Hg}, \mathrm{Fe}, \mathrm{Ni}, \mathrm{Pb}, \mathrm{Zn}$ ) was determined using EPA 200.7 methods, as well as an ICAP 6300 ICP optical emission spectrometer (ICP-OES). The concentration of $\mathrm{Hg}$ was determined by a flame atomic adsorption analyzer SensAA Dual (GBC Scientific Equipment Pty Ltd, Victoria, Australia).

\section{Data processing methods}

The experiment data were presented with mean of three tests with the presented summarized basic statistics of the dataset. Analysis of the interdependence of variables was carried out by calculating linear Pearson correlation coefficients. It has been assumed that the regression modeling of the potential usefulness of the selected variable (explanatory) to model another variable (explained variable) determines the absolute value of the high correlation coefficient between these two variables. The statistical analysis usually assumes that if the correlation coefficient is $>0.9$, a very strong linear dependence exists; 0.7-0.9 - significant linear dependence; 0.4-0.7 - moderate linear dependence; 0.2-0.4 - distinct linear dependence, but low; $<0.2$ - no linear dependence (Goon et al., 1986). 


\section{RESULTS AND DISCUSSION}

The seasonal and annual averages of physicochemical characteristics are given in Table 2 . The $\mathrm{pH}$ is an important factor that determines the suitability of water for a variety of purposes, inter alia, for irrigation. The tested samples showed $\mathrm{pH}$ values from neutral to slightly alkaline during the second cycle of sampling a growing trend (Figure 2). This may be a drought which influences on an increased flow of wastewater from agriculture and households, and as well on intensive microbial activity. well to a class for irrigation water. By classification of U.S. Salinity Laboratory, all of the samples belong to the $C_{2} S_{1}$ class of water, where ECW values range from 0.250 to $0.750 \mathrm{dSm}^{-1}$ and, as such, it can be used for irrigation of the plants with medium tolerance to salt.

Total dissolved solids (TDS) are an important characteristic for determination of the quality of water for irrigation because it expresses the total concentration of soluble salts in water. Dissolved solids in water include all inorganic salts, silica and soluble

Table 2. Average values of the water quality parameters of irrigation water, along with the standard limits by Republic of Serbia and irrigation water by US and FAO.

\begin{tabular}{|c|c|c|c|c|}
\hline \multirow[b]{2}{*}{ Parameters } & \multirow[b]{2}{*}{ Mean \pm STDEV } & \multicolumn{3}{|c|}{ Standard limits } \\
\hline & & $\begin{array}{c}\text { Ayers and } \\
\text { Westcot, } 1994\end{array}$ & $\begin{array}{l}\text { U.S irrigation } \\
\text { water quality }\end{array}$ & $\begin{array}{c}\text { Official Gazette } \\
\text { of Republic } \\
\text { Serbia, } \\
1994 / 2012\end{array}$ \\
\hline $\mathrm{pH}$ & $8.19 \pm 0.13$ & & $6.5-8.4$ & \\
\hline $\mathrm{ECw} 25^{\circ} \mathrm{C}\left(\mathrm{dSm} \mathrm{m}^{-1}\right)$ & $0.43 \pm 0.09$ & $0.7-2$ & $<0.7$ & \\
\hline $\operatorname{TDS}\left(\mathrm{mg}^{-\mathrm{I}^{-1}}\right)$ & $346.15 \pm 122.26$ & $500-1500$ & $<450$ & \\
\hline As (mg..$\left.^{-1}\right)$ & $0.008 \pm 0.015$ & & & 0.05 \\
\hline $\mathrm{B}\left(\mathrm{mg} \cdot \mathrm{I}^{-1}\right)$ & $0.109 \pm 0.085$ & & & 1.0 \\
\hline $\mathrm{Cd}\left(\mathrm{mg} . \mathrm{I}^{-1}\right)$ & bdl & & 0.01 & 0.01 \\
\hline $\mathrm{Cr}\left(\mathrm{mg} . \mathrm{I}^{-1}\right)^{\prime}$ & $0.001 \pm 0.001$ & & 0.1 & 0.5 \\
\hline $\mathrm{Cu}\left(\mathrm{mg} . .^{-1}\right)$ & $0.001 \pm 0.001$ & & 0.2 & 0.1 \\
\hline $\mathrm{Fe}\left(\mathrm{mg} \cdot .^{-1}\right)$ & $0.072 \pm 0.045$ & 5.0 & 5.0 & \\
\hline $\mathrm{Ni}\left(\mathrm{mg} . \mathrm{I}^{-1}\right)$ & $0.003 \pm 0.001$ & & 0.2 & 0.1 \\
\hline $\mathrm{Pb}\left(\mathrm{mg}^{\left.-I^{-1}\right)}\right.$ & $0.003 \pm 0.002$ & & 5.0 & 0.1 \\
\hline $\mathrm{Zn}\left(\mathrm{mg} . \mathrm{I}^{-1}\right)$ & $0.022 \pm 0.041$ & & 2.0 & 1.0 \\
\hline $\mathrm{Hg}\left(\mathrm{mg} . \mathrm{I}^{-1}\right)$ & bdl & & & 0.001 \\
\hline
\end{tabular}

Conductivity is a measure of the ability of an aqueous solution to carry an electric current. Increasing levels of conductivity and cat ions are the products of decomposition and mineralization of organic materials (Begum and Harikrishnarai, 2008). The aqueous salt solution and dissociated are broken down into positive and negative ions. Electrical conductivity in natural waters is generally with values less than usual. Measurement of the conductivity is performed at a specific temperature and it corresponds to the presence of dissolved salts. These are most commonly sodium chloride, and may be present, and sodium sulphate, calcium chloride, calcium sulfate, magnesium chloride, etc. Salts dissolved in the water influence on increase of the water conductivity values. In all three cycles of analyzing the water from Kolubara River (Figure 3), according to FAO classification, the samples belong to a class of water for drinking and irrigation, and as organic matter (Atekwana et al., 2004; Ahipathy and Puttaiah, 2006). Pure water must be free from most suspended particles, which are responsible for turbidity. TDS was the highest in summer due to evaporation and reduced intake, which contributed to an increase in concentration, and had the minimum value in the rainy season, due to the increased entry of rain and a corresponding reduction in concentration at all locations (Figure 4). The contents of trace elements and heavy metals in the samples of water are generally below the maximum allowable concentration (MAC). In sampling point No. 2,3,4 in the second series of sampling it was recorded an increased arsenic content above the MAC 10.0595 $\mathrm{mg}^{-1} ; 0.0634 \mathrm{mg} \mathrm{H}^{-1} ; 0.0641 \mathrm{mg}^{-1}$ ) (Figure 5). As it is in the zone below the rural village, it is possible that this increase was caused by increased anthropogenic activity, since in other series an increased content of this element was not registered. Correlation 
coefficients between various physicochemical parameters are shown in Table 3. It shows the correlation between the samples and the characteristics of the water where the $\mathrm{pH}$ value has a significant negative correlation to all studied parameters except to the concentration of $\mathrm{Cr}$, Fe and $\mathrm{Zn}$. ECW values were positively correlated to all studied parameters except to the concentration of $\mathrm{Cr}$, $\mathrm{Cu}$ and $\mathrm{Fe}$. TDS values show a positive correlation to the concentration of $\mathrm{As}, \mathrm{B}, \mathrm{Cd}, \mathrm{Cu}, \mathrm{Ni}$ and $\mathrm{Pb}$, and a negative to the concentration of $\mathrm{Cr}$, Fe and $\mathrm{Zn}$ in the samples of water.

Correlation coefficients between various physicochemical parameters are shown in Table 3. It shows the correlation between the samples and the characteristics of the water where the $\mathrm{pH}$ value has a

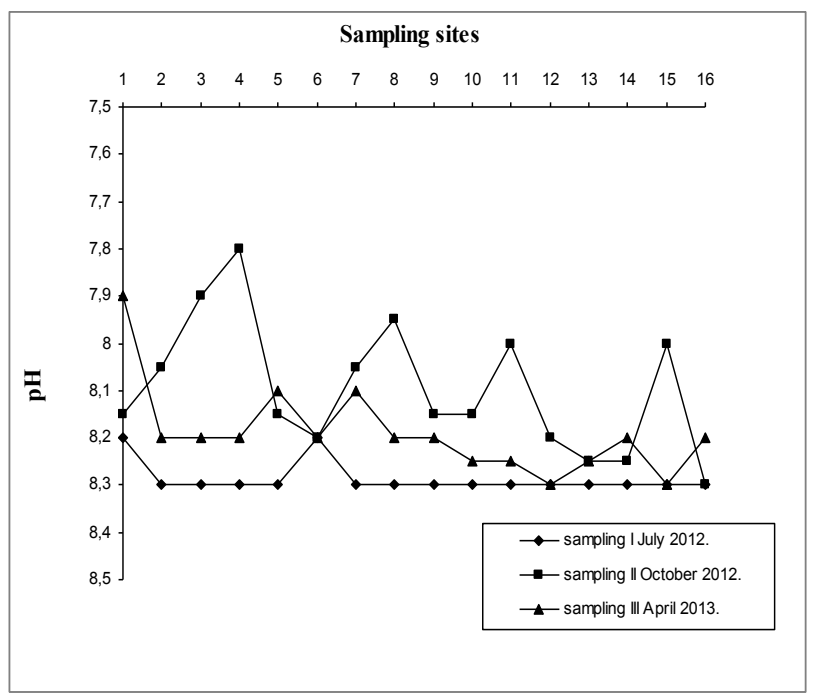

Figure 2. $\mathrm{pH}$ value of the tested water samples in batches of monitoring

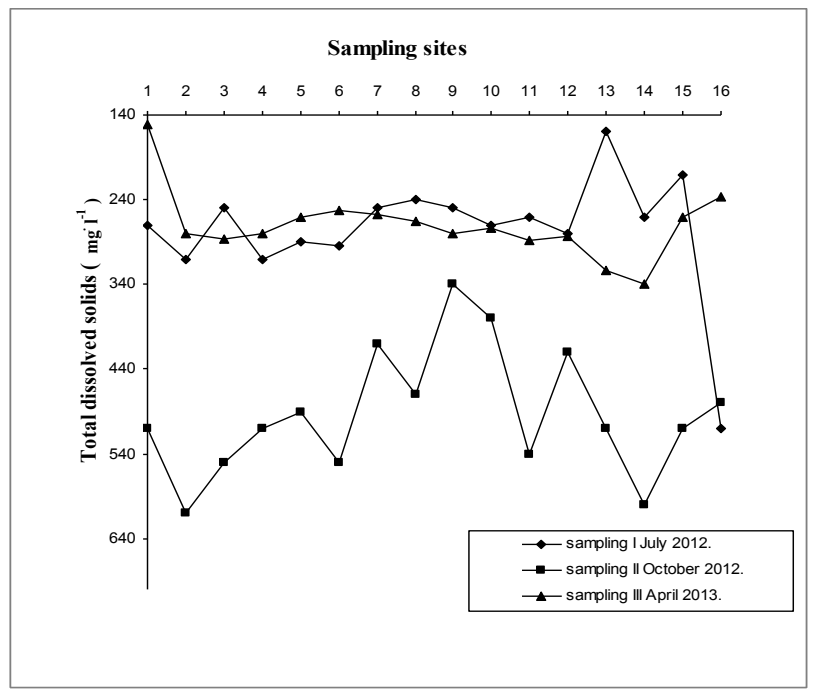

Figure 4. TDS value of the tested water samples in batches of monitoring significant negative correlation to all studied parameters except to the concentration of $\mathrm{Cr}$, Fe and Zn. ECW values were positively correlated to all studied parameters except to the concentration of $\mathrm{Cr}$, $\mathrm{Cu}$ and Fe. TDS values show a positive correlation to the concentration of $\mathrm{As}, \mathrm{B}, \mathrm{Cd}, \mathrm{Cu}, \mathrm{Ni}$ and $\mathrm{Pb}$, and a negative to the concentration of $\mathrm{Cr}$, Fe and $\mathrm{Zn}$ in the samples of water.

The obtained results also implies on significant linear dependence for $E C W$-B in the studied water samples, moderate linear dependence for ECW-TDS; ECW-Pb; TDS-As; TDS-B; TDS-Pb; As-B; As-Pb; B-Cd; BNi-Cr; B-Pb and distinct linear dependence for ECW-As; ECW-Cd; ECW-Ni; TDS-Cd; TDS-Ni; As-Cd; As-Ni; Cd-Pb; Cr-Fe; $\mathrm{Cr}-\mathrm{Ni}$; $\mathrm{Fe}-\mathrm{Zn}$; Ni-Pb; Pb-Zn while for the rest of observed parameters there is no linear dependence.

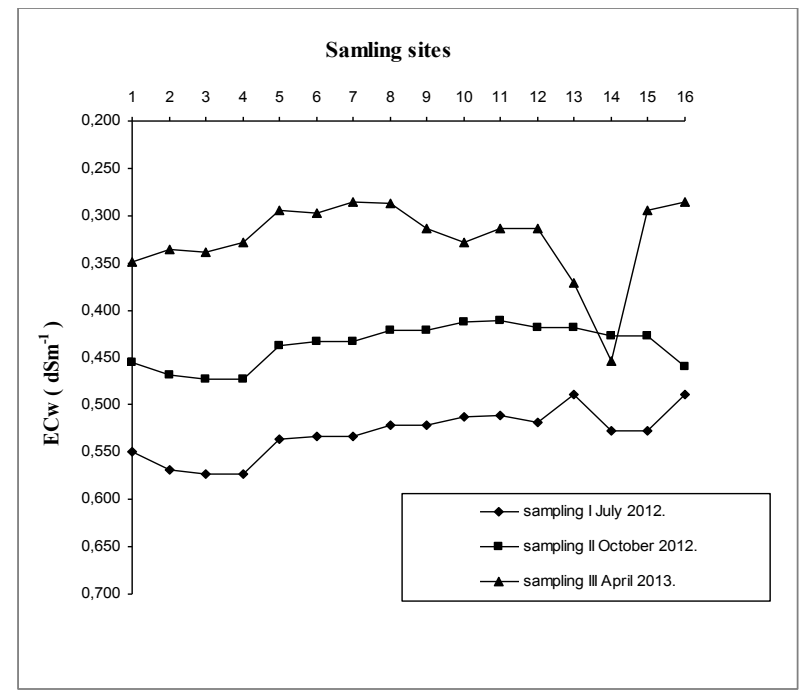

Figure 3. ECW value of the tested water samples in batches of monitoring

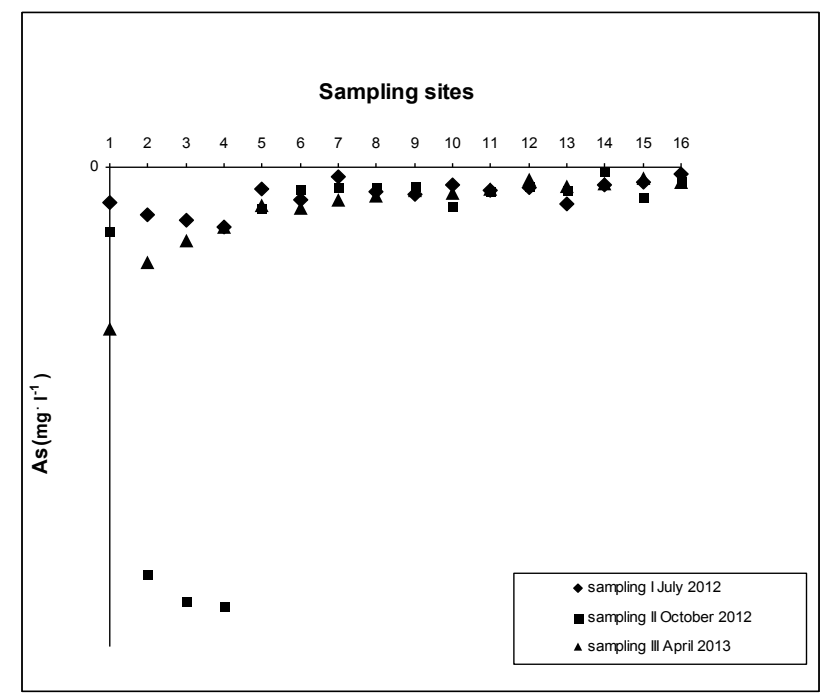

Figure 5. As concentration of the tested water samples in batches of monitoring 
Table 3. Correlation coefficients between water characteristics in Kolubara river $(n=48)$

\begin{tabular}{|c|c|c|c|c|c|c|c|c|c|c|c|c|}
\hline & $\mathrm{pH}$ & ECW & TDS & As & B & $\mathrm{Cd}$ & $\mathrm{Cr}$ & $\mathrm{Cu}$ & $\mathrm{Fe}$ & $\mathrm{Ni}$ & $\mathrm{Pb}$ & $\mathrm{Zn}$ \\
\hline $\mathrm{pH}$ & 1 & $\begin{array}{c}- \\
0.058\end{array}$ & $\begin{array}{c}- \\
0.427\end{array}$ & $\begin{array}{c}- \\
0.646\end{array}$ & $\begin{array}{c}- \\
0.475\end{array}$ & $\begin{array}{c}- \\
0.043\end{array}$ & 0.069 & $\begin{array}{c}- \\
0.224\end{array}$ & 0.031 & $\begin{array}{c}- \\
0.506\end{array}$ & $\begin{array}{c}- \\
0.177\end{array}$ & 0.235 \\
\hline ECW & & 1 & 0.465 & 0.221 & 0.725 & 0.399 & $0 . \overline{437}$ & $0 . \overline{1} 44$ & $0 . \overline{4}$ & 0.261 & 0.616 & 0.194 \\
\hline TDS & & & 1 & 0.656 & 0.677 & 0.352 & $0 . \overline{329}$ & 0.071 & $0 . \overline{4} 18$ & 0.252 & 0.594 & 0.068 \\
\hline As & & & & 1 & 0.510 & 0.373 & $0 . \overline{159}$ & $\begin{array}{c}- \\
0.014\end{array}$ & $0 . \overline{1}$ & 0.291 & 0.453 & 0.128 \\
\hline B & & & & & 1 & 0.660 & $0 . \overline{237}$ & 0.050 & $\begin{array}{c}- \\
0.453\end{array}$ & 0.608 & 0.486 & $\begin{array}{c}- \\
0.072\end{array}$ \\
\hline $\mathrm{Cd}$ & & & & & & 1 & $0 . \overline{-}$ & $0 . \overline{314}$ & $\begin{array}{c}- \\
0.510\end{array}$ & $0 . \overline{125}$ & 0.348 & 0.019 \\
\hline $\mathrm{Cr}$ & & & & & & & 1 & $0 . \overline{1} 73$ & 0.264 & 0.255 & $0 . \overline{133}$ & 0.002 \\
\hline $\mathrm{Cu}$ & & & & & & & & 1 & $0 . \overline{2} 39$ & $0 . \overline{1} 03$ & $0 . \overline{116}$ & $0 . \overline{1} 152$ \\
\hline $\mathrm{Fe}$ & & & & & & & & & 1 & 0.065 & $0 . \overline{124}$ & 0.303 \\
\hline $\mathrm{Ni}$ & & & & & & & & & & 1 & 0.246 & 0.808 \\
\hline $\mathrm{Pb}$ & & & & & & & & & & & 1 & 0.254 \\
\hline $\mathrm{Zn}$ & & & & & & & & & & & & 1 \\
\hline
\end{tabular}

\section{CONCLUSION}

Results from water samples showed that the concentration of heavy metals in the water of the river Kolubara in most of the samples analyzed is within the MAC values. Variations of the content of heavy metal concentrations in the water are the result of a wide range of human activities (primarily agriculture) in the study area and water levels throughout the year.

Based on the obtained and analyzed results of testing the quality of water for irrigation from the Kolubara River, it can be concluded that it can be used for irrigation of crops and soil with frequent quality checks during the summer months.

\section{ACKNOWLEDGMENT}

This research was financially supported by the Ministry of Education and Science, Republic of Serbia [Project TR 37006]

\section{REFERENCES}

Ahipathy, M.V., Puttaiah, E.T., 2006. Ecological characteristics of Vrishabhavathy River in Bangalore (India) Environ Geol 49: 1217-1222.

Atekwana, E.A., Atekwana Estella A., Rowe, R.S., Werkema, D.D. Jr.,Legall, F.D., 2004. The relationship of total dissolved solids measurements to bulk electrical conductivity in an aquifer contaminated with hydrocarbon, J Appl Geophys 56: 281-294.

Ayers, R.S., Wescot, D.W., 1994. Water Quality for Agriculture, Irrigation and Drainage paper 29, Rev. 1 .
Begum, A., Harikrishna R., 2008. Study on the Quality of Water in Some Streams of Cauvery River. J. Chem. 2, 377-384.

Determination of electrical conductivity SRPS EN 27888:1993.

Doneen, L.D., Westcot, D.W., 1988. FAO Irrigation practice and water management Irrigation and Drainage Paper 1, Rev.1.

Duncan, R.R., Carow R.N., Huck, M., 2000.USGA Green Section Record, September /October 2000, 14.

FAO, 1954. U.S. Salinity Laboratory Staff.

Faniran, J.A., Ngceba, F.S., Bhat, R.B., Oche, C.Y., 2001. An assessment of the water quality of the Isinuka springs in the Transkei region of Eastern Cape, Republic of South Africa. Water SA 27 (2) 241-250.

Fatoki, O.S., Lujiza, N., Ogunfowokun, O.A. ,2005. Trace metal pollution in Umtata river, Water S.A. 28(2), 183.

Goon A. M., Gupta, M. K., Dasgupta, B. ,1986. Fundmental of Statistics, The World Press Pvt. Ltd. Calcutta, Vol I.

Greenberg, A.E., Clesceri, L.S.,Eato, A.D. , 1998. Standard Methods for the Examination of Water and Wastewater, American Public Health Association, 20th ed.,Washington, U.S.A.

http://sh.wikipedia.org/wiki/Kolubara

Konstandinova, G., Georgieva, N., Yaneva, Z., Petkov, G.,Todorova, M., Miteva,Ch. , 2013. Tundzha River water quality as a source for irrigation in agriculture Bulg J Agric Sci, 19 (No 4) 2013, 635-643. 
Measurement of $\mathrm{pH}$ - Potentiometric method SRPS H.Z1.111:1987

Official Gazette of Republic Serbia, 23/94, 1994 and \#50/2012, 2012.

Simeonov, V, Stratis, J.A., Samara, C., Zachariadis, G.,Voutsa D., Anthemidis, A., Sofoniou, M., Kouimtzis, T., 2003. Assessment of the surface water quality in Northern Greece. Water Research 37: 4119-4124.
Tanasijević, Đ., Antonović, G., Aleksić, Ž., Pavićević, N., Filipović, Đ., Spasojević, M., 1966. The Soils of the west and northwestern Serbia, Institute of Soil Science in Topčider, Belgrade, Yugoslavia (in Serbian). 